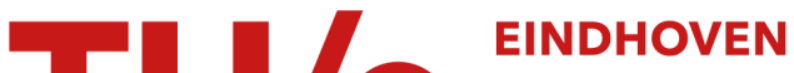 UNIVERSITY OF TECHNOLOGY
}

\section{Burden of disease of people with epilepsy during an optimized diagnostic trajectory}

Citation for published version (APA):

Wijnen, B. F. M., Schat, S. L., de Kinderen, R. J. A., Colon, A. J., Ossenblok, P. P. W., \& Evers, S. M. A. A. (2018). Burden of disease of people with epilepsy during an optimized diagnostic trajectory: costs and quality of life. Epilepsy Research, 146, 87-93. https://doi.org/10.1016/j.eplepsyres.2018.07.024

\section{Document license:}

TAVERNE

DOI:

10.1016/j.eplepsyres.2018.07.024

Document status and date:

Published: 01/10/2018

\section{Document Version:}

Publisher's PDF, also known as Version of Record (includes final page, issue and volume numbers)

\section{Please check the document version of this publication:}

- A submitted manuscript is the version of the article upon submission and before peer-review. There can be important differences between the submitted version and the official published version of record. People interested in the research are advised to contact the author for the final version of the publication, or visit the $\mathrm{DOI}$ to the publisher's website.

- The final author version and the galley proof are versions of the publication after peer review.

- The final published version features the final layout of the paper including the volume, issue and page numbers.

Link to publication

\section{General rights}

Copyright and moral rights for the publications made accessible in the public portal are retained by the authors and/or other copyright owners and it is a condition of accessing publications that users recognise and abide by the legal requirements associated with these rights.

- Users may download and print one copy of any publication from the public portal for the purpose of private study or research.

- You may not further distribute the material or use it for any profit-making activity or commercial gain

- You may freely distribute the URL identifying the publication in the public portal.

If the publication is distributed under the terms of Article 25fa of the Dutch Copyright Act, indicated by the "Taverne" license above, please follow below link for the End User Agreement:

www.tue.nl/taverne

Take down policy

If you believe that this document breaches copyright please contact us at:

openaccess@tue.nl

providing details and we will investigate your claim. 


\title{
Burden of disease of people with epilepsy during an optimized diagnostic trajectory: costs and quality of life
}

\author{
Ben F.M. Wijnen ${ }^{\mathrm{a}, \mathrm{b}, \mathrm{f}, 1, *}$, Scarlett L. Schat ${ }^{\mathrm{b}, \mathrm{f}, 1}$, Reina J.A. de Kinderen ${ }^{\mathrm{a}, \mathrm{f}}$, Albert J. Colon ${ }^{\mathrm{c}, \mathrm{f}}$, \\ Pauly P.W. Ossenblok ${ }^{\mathrm{d}, \mathrm{e}, \mathrm{f}}$, Silvia M.A.A. Evers ${ }^{\mathrm{a}, \mathrm{b}, \mathrm{f}}$ \\ ${ }^{a}$ Trimbos Institute, Centre for Economic Evaluations, Netherlands Institute of Mental Health and Addiction, Utrecht, The Netherlands \\ ${ }^{\mathrm{b}}$ Department of Health Services Research, Maastricht University, Maastricht, The Netherlands in collaboration with CAPHRI School for Public Health and Primary Care, \\ Maastricht University, Maastricht, The Netherlands \\ ${ }^{\mathrm{c}}$ Department of Research \& Development, Epilepsy Centre Kempenhaeghe, Heeze, The Netherlands \\ d Department of Clinical Neurophysiology, Academic Center for Epileptology Kempenhaeghe/MUMC, Heeze, The Netherlands \\ e Department of Clinical Physics, Epilepsy center Kempenhaeghe, Heeze, The Netherlands \\ ${ }^{\mathrm{f}}$ Department of Biomedical Engineering, Eindhoven University of Technology, Den Dolech 2, 5612 AZ Eindhoven, The Netherlands
}

\section{A R T I C L E I N F O}

\section{Keywords:}

Epilepsy

EEG

MEG

Diagnosis

Cost of illness

Quality of life

\begin{abstract}
A B S T R A C T
Background: Diagnosing epilepsy can be lengthy and stressful, potentially leading to increased use of healthcare resources and a reduction in quality of life.

Aim: This study aims to determine cost and quality of life before and after an optimized diagnostic procedure for people suspected of having epilepsy from a societal perspective with a follow-up of 12 months. In addition, this study aims to differentiate between people diagnosed with epilepsy during the follow-up of the study and the people who are diagnosed as not having epilepsy or for whom diagnosis is still uncertain.

Methods: A questionnaire regarding the use of healthcare resources was used accompanied by the EQ-5D-3 L. Multiple imputations by chained equations with predictive mean matching was used to account for missing data. To investigate the uncertainty of the results, non-parametric bootstrapped (1000 times) was used.

Results: In total, 116 people were included in the study. Total average costs per patient made in the previous 3 months had decreased from $€ 4594$ before the optimized diagnostic trajectory to $€ 2609$ in the 12 months after the optimized diagnostic trajectory. Healthcare costs were the largest expense group (52-66\%) and had decreased significantly from baseline measurement to 12 months after baseline ( $€ 2395$ vs $€ 1581$ ). Productivity costs had decreased from $€ 1367$ to $€ 442$ per 3 months. Total annual costs were similar between people diagnosed with epilepsy during the follow-up of the study and the people who are diagnosed as not having epilepsy or for whom diagnosis is still uncertain. Quality of Life had significantly increased over the course of 12 months from 0.80 to 0.84 (Dutch tariff).

Discussion: This study indicates that an optimized diagnostic trajectory has positively influenced the use of healthcare resources and the quality of life in people with epilepsy. As chronic care patients make diverse costs, future research should identify the long-term costs after an optimized diagnostic trajectory for patients with epilepsy, possibly identifying patients who are at high risk of becoming high-cost users in the future for early intervention.
\end{abstract}

\section{Background}

Correctly diagnosing epilepsy poses a great clinical challenge, as misdiagnosis is common and differentiation is not always a straightforward process (Chadwick and Smith, 2002). The condition has a complicated clinical appearance, as its progression varies per patient. Its symptoms are diverse and often ambiguous (Pugliatti et al., 2007), which makes distinguishing epilepsy from similar disorders a major difficulty in establishing the correct diagnosis (Chadwick and Smith, 2002).

\footnotetext{
* Corresponding author at: Duboisdomein 30, 6229 GT Maastricht, P.O. Box 616, 6200, MD, Maastricht, The Netherlands.

E-mail addresses: b.wijnen@maastrichtuniversity.nl (B.F.M. Wijnen), s.schat@alumni.maastrichtuniversity.nl (S.L. Schat), reina.dekinderen@maastrichtuniversity.nl (R.J.A. de Kinderen), colona@kempenhaeghe.nl (A.J. Colon), ossenblokp@kempenhaeghe.nl (P.P.W. Ossenblok), s.evers@maastrichtuniversity.nl (S.M.A.A. Evers).

${ }^{1}$ Co-first authorship, authors contributed equally.
} 


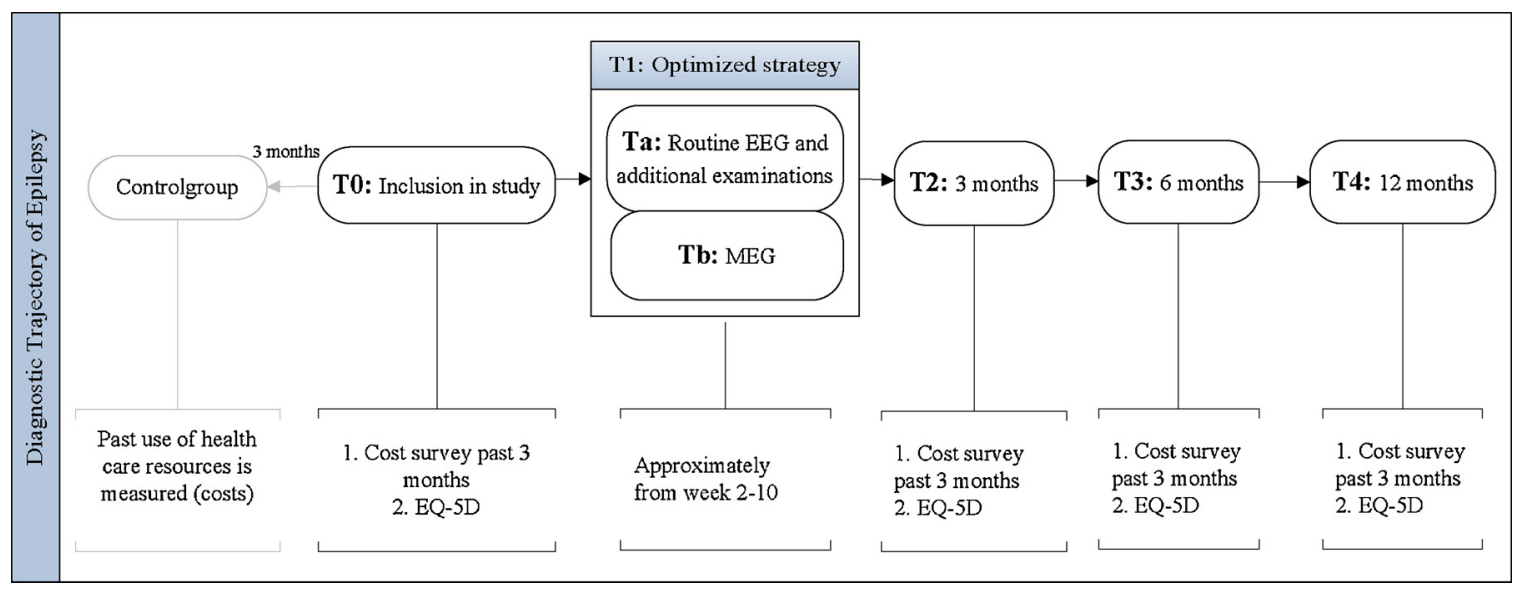

Fig. 1. Diagnostic trajectory of the study with an optimized trajectory.

Epilepsy has a considerable impact on costs and Quality of Life. It is often paired with psychological states of anxiety and depression, behavioral issues and cognitive dysfunction (Ramaratnam et al., 2008). These associated psychosocial effects as well as the uncertain clinical nature of epilepsy lead to a significant impact on a person's Quality of Life (Baker et al., 1997). Moreover, epilepsy constitutes a considerably high socioeconomic impact in Europe. For example, in 2004, the total costs of epilepsy were estimated at $€ 15.5$ billion, constituting $0.3 \%$ of the total European healthcare expenditures. Similarly, healthcare costs in the Netherlands have been estimated at $€ 251$ million in 2007 (Slobbe et al., 2011). A study by Cockerell et al. shows that the average medical costs per patient with epilepsy decreases with nearly $70 \%$ at 2 years after diagnosis (Cockerell et al., 1994).

An adequate diagnosis of epilepsy requires differentiation between seizures and other neurological disturbances (Chadwick and Smith, 2002), for example psychogenic non-epileptic seizures (PNES), which is most frequently misdiagnosed as epilepsy (Benbadis, 2006). In the search for a correct diagnosis, persons may excessively use health care resources, leading to higher health care costs, and experience lower quality of life. As a result, the diagnostic trajectory of epilepsy can be a lengthy process based on trial-and-error, often experienced as stressful and uncomfortable (Noachtar and Rémi, 2009). In addition to this shopping behavior, they can experience stress and anxiety due to uncertainty about their diagnosis, leading to a lower Quality of Life. Determining the correct diagnosis in people suspected of having epilepsy can have great consequences for their health, social behavior and employment (Angus-Leppan, 2008), and can be crucial in minimizing their healthcare consumption and in improving Quality of Life.

No studies up till now have provided insight into which costs people with possible epilepsy make during this diagnostic process and how it influences their Quality of Life, in order to determine how and where efficiency can be increased in the process of diagnosing and treating epilepsy. This study aims to quantify the Burden of Disease, in terms of quality of life and (healthcare) resource use, before and after an optimized diagnostic procedure for people with suspected epilepsy from a societal perspective with a follow-up of 12 months. In addition, this study aims to differentiate between people diagnosed with epilepsy during the follow-up of the study and the people who are diagnosed as not having epilepsy or for whom diagnosis is still uncertain. Assessing the burden of disease will consist of two components: 1) measuring cost of illness, operationalized in costs and use of (healthcare) resources, and 2) measuring health-related quality of life, operationalized in quality-adjusted life years (QALYs).

\section{Methods}

The study was a Burden of Disease study, which was assessed by two components: measuring the Cost-of-Illness (CoI), operationalized in cost, and measuring the Health-Related Quality of Life (HR-QoL), operationalized in utilities and Quality-Adjusted Life Years (QALYs). A CoI study aims to identify and measure all the costs of a particular disease. The output reflects the total burden of a specific disease to society (Rice, 1994). QALYs are widely used measures for health outcome that combine mortality and morbidity into a single measure (Kind et al., 2009). QALYs are generated by using health utilities, which are preference weights that reflect the value of a certain outcome (Weinstein et al., 2009).

\subsection{Design and data collection}

The study was a prospective, non-randomized, longitudinal study with a pre-post comparison. In this pre-post design, the same patients were measured before and several times during and after the diagnostic trajectory, i.e. patients serve as their own controls (3-month period before baseline). This study was funded by a healthcare innovation project which enabled access to the optimized diagnostic trajectory.

Data was collected at baseline and after 3, 6 and 12 months. Baseline measures were performed at the start of the diagnostic trajectory (T0). Participants received a questionnaire regarding their use of healthcare resources in the past 3 months and the Dutch EuroQol-5D 3 level version (EQ-5D-3 L) (Van Reenen and Oppe, 2015). The baseline questionnaire also included questions on general characteristics, i.e. date of birth, gender, education, civil status and whether participants autonomously filled in the questionnaire or proxies were used.

Recruited participants were derived from a larger healthcare innovation project in which an optimized diagnostic trajectory was examined that included magnetoencephalography (MEG) in addition to the standard routine diagnostic trajectory. Before the start of the study, the attendant neurologist notified the patient of the request for a routine EEG. During this conversation, the patient was asked to participate in the optimized diagnostic trajectory including the MEG procedure, provided that they met the inclusion criteria. The patient received information about the study and an informed consent form. The patient was given 2 weeks to review and ask questions. Fig. 1 gives an overview of the diagnostic trajectory. At T0, patients were included in the study. After they gave permission, the research nurse provided them with the relevant documents, including the cost questionnaire, the EQ-5D-3 L, and a reply envelope. Subsequently, the routine EEG and MEG were scheduled. During week 2-10 (T1), the optimized diagnostic trajectory took place. After 3, 6, and 12 months (T2-T4), the cost questionnaire and EQ-5D were again administered. The study protocol was approved by the Medical Ethics Committee of Kempenhaeghe. 


\subsection{Optimized trajectory}

The study comprised an optimized trajectory, i.e. all patients had been subjected to a routine EEG, any additional examinations, i.e. an EEG after sleep deprivation and/or a 24-hour EEG and/or an MRI, and a MEG. Together they were intended to form an optimized trajectory in order to minimize the burden of epilepsy.

\subsection{Sample}

The sample consisted of patients enrolled at the Academic Center for Epileptology, Kempenhaeghe, located in Heeze, the Netherlands. Participants eligible for the study were patients suspected of having epilepsy for whom a standard EEG was requested for the first time by the attending neurologist. As the sample originated from research on the effectiveness of MEG, some exclusion criteria were established. Patients were excluded if they were under the age of 6 , if there was a high suspicion of non-epileptic seizures, if they were either uncooperative or claustrophobic, and/or in case of presence of intracranial metal.

\subsection{Cost analysis}

The following cost categories were identified (Hakkaart-van Roijen et al., 2015); healthcare costs, patient and family costs, and costs in other sectors (Drummond et al., 2005). Self-administered retrospective questionnaires were used to measure costs. If desired, a copy of the questionnaire can be requested from the corresponding author.

Healthcare costs were determined by measuring the amount of consultations with healthcare professionals, the use of diagnostic methods, and the frequency of inpatient stay and outpatient treatment was measured. These costs were derived from the Dutch guidelines (Hakkaart-van Roijen et al., 2015). Additionally, the use of AEDs and other drugs was measured. To determine the costs of these drugs, the website of the Dutch healthcare institute for the cost of pharmaceuticals (www.medicijnkosten.nl) was used. These costs were calculated per unit and subsequently multiplied with the reported dosage.

Patient and family costs, including the use of formal care, informal care, and medical devices, were determined according to the Dutch guidelines (Hakkaart-van Roijen et al., 2015). The costs for informal care were valued using the proxy good method. This method values the time spent on informal care at the labor price of a close market substitute. Consequently, the hourly wage of informal care amounted to $€ 14.08$ (Hakkaart-van Roijen et al., 2015). When standard prices of devices were not available, market prices applied.

Costs in other sectors, i.e. productivity losses due to absence from work, were measured using standard prices for productivity costs for paid work. The Dutch guidelines recommend using the friction cost method to determine productivity losses, which implies that long-term absent employees can be replaced. Hence, productivity costs were calculated based on the average period an employer needs to replace a sick employee, which is the friction period. In accordance with the Dutch guidelines, a friction period of 85 days and hourly wages of $€ 3496$ were applied in this study (Hakkaart-van Roijen et al., 2015).

To correct for the effects of inflation, all costs were converted and applied to 2015 by use of the Consumer Price Index (www.statline.cbs. $\mathrm{nl})$.

\subsection{HR-QoL analysis}

To measure the HR-QoL among respondents, utilities were used. Utilities reflect morbidity or quality of a particular health state in a number ranging from 0 to 1 (Kind et al., 2009; Drummond et al., 2005). The EQ-5D-3 L was used to measure these utilities. This multi-attribute instrument is intended for self-completion by respondents and contains 5 dimensions of HR-QoL. Each dimension could be rated at three levels: no problems, some problems, and major problems (Van Reenen and Oppe, 2015). For each health state of the EQ-5D, utility values were calculated using the Dutch tariff (Lamers et al., 2005). This tariff is derived from preferences elicited from the general population. The EQ5D also includes a Visual Analogue Scale (VAS), ranging from zero (worst imaginable health state) to 100 (best imaginable health state) (Van Reenen and Oppe, 2015).

Using the generated utilities, QALYs could be calculated by calculating the area under the curve.

\subsection{Statistical analysis}

All analyses were conducted using SPSS ${ }^{\odot}$ (version 23) and STATA 14. The intention-to-treat principle was used, in which all participants of whom baseline data were available were analyzed. It is important to notice that with regards to cost, participants' missing values may imply that they did not use a particular resource rather than having forgotten to fill in the options. Hence, missing values of people who had skipped an entire section were imputed using mean imputation. For completely missing observation (i.e. people did not return the questionnaire) we used multiple imputations by chained equations with predictive mean matching to account for the missing data. This technique was used to account for non-normality of the cost and utility data. Using predictive mean matching "real" observed values from similar cases are imputed instead of imputing regression estimates (Grittner et al., 2011; Horton and Lipsitz, 2001). Moreover, the use of this technique may avoid bias associated with complete case analyses and makes optimally use of available data. Imputations were based on age, gender, marital status, education, and whether people had a paid job. Annual costs were calculated by assuming the last observation carried backwards from 12 months follow-up.

To identify difference in utilities over time, a (generalized) linear mixed model was used to account for the hierarchical structure of the data (e.g. repeated measurements). This model constitutes the recommended approach to longitudinal designs as estimates are based on all available data. Random- and repeated effects were determined based on model fit, (a-priori implemented with random intercepts and slopes for individuals). Utilities were entered as dependent variable, and time point (i.e., 3 months, 6 months, 12 months), gender, age, civil status, education, employment ( $>12 \mathrm{~h}$ ), and eventual diagnosis of epilepsy were added as independent variables. Given the non-normality of the data, non-parametric bootstrapping (1000 replications) was performed in order to investigate the uncertainty around the cost and utilities, and to compute $95 \%$ confidence intervals (CI) based on the $2,5^{\text {th }}$ and $97,5^{\text {th }}$ percentiles. Subgroup analyses were performed in which people who were diagnosed as having epilepsy during the follow-up of the study were compared to people who were diagnosed as not having epilepsy or for whom diagnosis was still uncertain after 12 months.

\section{Results}

In total, 116 participants were included in the study between August 2013 and March 2016 and were able to fill in the baseline questionnaire. Their mean age was 37 (7-77). Nearly 52\% of participants were male. The majority of participants were either married or cohabiting, and had finished secondary school. See Table 1 for group characteristics. After 12 months follow-up, 76 people (69.7\%) were diagnosed as having epilepsy and 33 people $(30.3 \%)$ were diagnosed as not having epilepsy or the diagnosis was still uncertain, 7 people dropped-out and hence, no information was available.

\subsection{Costs}

The mean total costs per participant at baseline were $€ 4594$ per three months (see Table 2). The largest expenses throughout the study were healthcare costs (52-66\%). The largest cost item within the 
Table 1

Group characteristics at baseline $(\mathrm{N}=116)$.

\begin{tabular}{|c|c|c|}
\hline Characteristics & & $\%(\mathrm{~N})^{\mathrm{a}}$ \\
\hline \multirow[t]{2}{*}{ Gender } & Male & $51.8(59)$ \\
\hline & Female & $48.2(55)$ \\
\hline \multirow[t]{4}{*}{ Age } & $7-20$ & $18.8(21)$ \\
\hline & $21-40$ & $36.6(41)$ \\
\hline & $41-60$ & $31.3(35)$ \\
\hline & $>60$ & $13.4(15)$ \\
\hline \multirow[t]{4}{*}{ Civil status } & Married/cohabiting & $69(78)$ \\
\hline & Living alone & $14.2(16)$ \\
\hline & Living with parents or guardians & $7.1(8)$ \\
\hline & Other & $9.7(11)$ \\
\hline \multirow[t]{6}{*}{ Education } & No education & $0.9(1)$ \\
\hline & Primary school & $11.7(13)$ \\
\hline & Pre-vocational secondary school & $9(10)$ \\
\hline & Secondary school & $52.3(58)$ \\
\hline & Higher education & $20.7(23)$ \\
\hline & Special education & $5.4(6)$ \\
\hline \multirow[t]{2}{*}{ Employment ( > 12 h) } & Employed & $49.6(56)$ \\
\hline & Unemployed & $50.4(57)$ \\
\hline \multirow[t]{2}{*}{ Absenteeism } & Has been absent from work & $66.1(37)$ \\
\hline & Has not been absent from work & $33.9(20)$ \\
\hline \multirow[t]{3}{*}{ Questionnaire completed by } & Participant themselves & $78.1(89)$ \\
\hline & Parent/caregiver & $15.8(18)$ \\
\hline & Other & $6.1(7)$ \\
\hline \multirow[t]{3}{*}{ Additional EEG } & 1 additional EEG & $84(77)$ \\
\hline & 2 additional EEGs & $2(2)$ \\
\hline & No additional EEG & $23(21)$ \\
\hline \multirow[t]{2}{*}{ EEG after sleep deprivation } & Yes & $3128)$ \\
\hline & No & 78 (72) \\
\hline \multirow[t]{2}{*}{$24 \mathrm{~h}-\mathrm{EEG}$} & Yes & 42 (39) \\
\hline & No & $67(61)$ \\
\hline \multirow[t]{2}{*}{ Other additional examinations } & Yes & 15 (14) \\
\hline & No & $94(86)$ \\
\hline
\end{tabular}

a Number of missing values per characteristic: gender: 2; age: 4; civil status: 3; education: 5; employment: 3 ; questionnaire completed by: 2 .

healthcare costs throughout the entire study was diagnostic procedures, followed by consultations and inpatient stay. All costs except for the costs related to diagnostic procedures had ultimately decreased after 12 months. Significant decreases were found in healthcare costs and patient and family costs. Patient and family costs decreased from $€ 832$ at baseline to $€ 585$ at the end of the study (Table 2). Overall, the 3monthly total costs decreased to $€ 2609$ at the end of the study. The average annual costs per patient were $€ 13,216$ (Table 2). Productivity losses decreased overtime from $€ 1376$ at baseline to $€ 442$ at 12 months follow-up. At baseline, there was a considerable difference between people who were eventually diagnosed as having epilepsy and those for whom diagnosis was still uncertain or who were not diagnose as having epilepsy (€5057 for the group with epilepsy compared to $€ 3722$ (see Table 3). Total annual costs were similar between both groups.

\subsection{Quality of life}

The average utilities significantly increased from 0.80 before to 0.84 one year after an optimized diagnostic procedure (after three 3 months, $\mathrm{p}=0.36$; after 6 months, $\mathrm{p}=0.31$; after 12 months, $\mathrm{p}=0.00$ ). The results show that immediately after the optimized diagnostic procedure there is already a (non-significant) increase in utilities. The overall QALY during the course of the study was 0.81 (Table 4). Moreover, people eventually diagnosed as having epilepsy had a slightly higher utility at baseline. However, the group diagnosed as not having epilepsy or for whom diagnosis was still uncertain demonstrated larger increases overtime. Hence, overall QALY was lower for the people diagnosed with epilepsy ( 0.81 compared to 0.83 ).

\section{Discussion}

The aim of this study was to quantify the Burden of Disease for people with possible epilepsy before and after an optimized diagnostic trajectory. The mean costs per patient made in the previous three months had decreased from $€ 4594$ before vs. $€ 2609$ in the 12 months after the optimized diagnostic trajectory. Healthcare costs and costs in other sectors had significantly decreased within 12 months of the study. At 3 months follow-up, the healthcare costs increased, which can be explained by the optimized diagnostic trajectory that took place between the baseline and 3-month-after measurement, which led to extra costs. Annual total costs were similar between people eventually diagnosed as having epilepsy and those that were diagnosed as not having epilepsy or for whom diagnosis was still uncertain. However, total costs per 3 months decreased earlier in the group who was diagnosed as having epilepsy, mainly due to a steep reduction in healthcare costs. This is likely to be explained by additional examinations in the other group.

Overall the utility had increased during the course of the study $(0.80$ vs. 0.84) using the Dutch tariff. The Quality of Life had directly increased after the optimized diagnostic trajectory occurred. This may suggest that the trajectory has had a positive effect on Quality of Life. However, utilities were slightly lower in the group eventually diagnosed as having epilepsy, ultimately leading to a lower overall QALY for this group.

A prospective Cost-of-Illness study for epilepsy in Italy found similar results regarding medication and hospital admission (Tetto et al., 2002). Furthermore, a study among privately insured people examined the burden of epilepsy in the United States and found average annual direct costs per patient with epilepsy to be $\$ 10,258$ in 2005 (approx. $€ 8,000-10,000$ in 2016), which is comparable to the annual healthcare cost demonstrated in this study (€8138). The study demonstrated similar average annual indirect costs per person (Ivanova et al., 2010).

To the best of our knowledge, there is no literature available on how a correct diagnosis influences the Quality of Life in people with epilepsy. However, few studies report an increase of Quality of Life due to certain interventions for epilepsy patients (Dodrill and Morris, 2001; Hosseini et al., 2016; Caller et al., 2016).

Several studies reported similar scores for Quality of Life, also using the EQ-5D. A study on the HR-QoL of patients before and after epilepsy surgery established an improvement in utilities from 0.81 at baseline to 0.91 at follow-up, consistent with our baseline findings. As this trial included an intervention, follow-up utilities can only be compared to a certain extent (Selai et al., 1999). Furthermore, a recent cross-sectional study on coping styles and Quality of Life in patients with partial epilepsy showed an average utility score of 0.80 among patients, identical to our findings at baseline (Westerhuis et al., 2011). Likewise, a study using a similar multi-attribute instrument found a mean value of 0.88 for the 15D utility (Stavem et al., 2001).

\subsection{Strengths and limitations}

A first strength of this study is that it lives up to scientific standards, as academic guidelines and reliable instruments were used (Hakkaartvan Roijen et al., 2015). Second, the study takes a broad perspective on the Burden of Disease, as many cost items were covered, especially costs related to informal care and productivity losses. This can be seen as an asset compared to other European studies, which often solely take healthcare costs into account. Last, this study applied a bottom-up approach, since the patients' perspective was adopted in collecting and quantifying data, which contributed to thoroughness of the results.

This study also has some limitations. First, due to the longitudinal design of the study, loss to follow-up of participants was common, threatening the validity of the study. However, multiple imputation was used to account for this loss and to make optimal use of the available data. A second limitation of the study is the fact that Kempenhaeghe is a 
Table 2

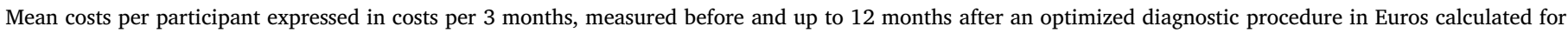
2015.

\begin{tabular}{|c|c|c|c|c|c|}
\hline$N$ & $\begin{array}{l}\text { Baseline }^{f} \\
116\end{array}$ & $\begin{array}{l}3 \text { months } \\
\text { after } \\
78\end{array}$ & $\begin{array}{l}6 \text { months } \\
\text { after } \\
80\end{array}$ & $\begin{array}{l}12 \text { months } \\
\text { after } \\
67\end{array}$ & $\begin{array}{l}\text { Total annual costs } \\
\text { after }^{\mathrm{e}}\end{array}$ \\
\hline Healthcare costs ${ }^{\mathrm{a}, \mathrm{d}}$ & $2395(52 \%)$ & $2989(66 \%)$ & $1987(57 \%)$ & $1581(61 \%)$ & $8138(62 \%)$ \\
\hline $95 \%$ CI & $2078-2737$ & $2514-3463$ & $1625-2348$ & $1387-1775$ & $7252-9025$ \\
\hline Consultations & 613 & 495 & 291 & 315 & \\
\hline GP & 63 & 41 & 31 & 29 & \\
\hline Neurologist & 250 & 195 & 114 & 79 & \\
\hline Paramedics & 34 & 27 & 26 & 28 & \\
\hline Mental health & 41 & 47 & 18 & 66 & \\
\hline Alternative care & 20 & 14 & 5 & 30 & \\
\hline Occupational health & 67 & 80 & 41 & 24 & \\
\hline Other specialists & 138 & 90 & 56 & 59 & \\
\hline Diagnostic procedures & 988 & 1360 & 1503 & 1072 & \\
\hline Routine EEG & 215 & 246 & 240 & 237 & \\
\hline EEGsd & 145 & 176 & 214 & 185 & \\
\hline 24-h EEG & 336 & 401 & 504 & 405 & \\
\hline MRI & 144 & 149 & 155 & 151 & \\
\hline Other & 147 & 183 & 390 & 93 & \\
\hline $\mathrm{MEG}^{\mathrm{c}}$ & & 213 & & & \\
\hline Cost of AEDs & 52 & 53 & 48 & 34 & \\
\hline Cost of other drugs & 14 & 10 & 13 & 14 & \\
\hline Inpatient stay & 466 & 632 & 186 & 199 & \\
\hline Epilepsy centre & 292 & 547 & 105 & 106 & \\
\hline General hospital & 163 & 63 & 17 & 93 & \\
\hline Academic hospital & 1 & 17 & 65 & 0 & \\
\hline Revalidation centre & 0 & 6 & 0 & 0 & \\
\hline Nursing home & 0 & 0 & 0 & 0 & \\
\hline Outpatient treatment & 263 & 203 & 24 & 54 & \\
\hline Epilepsy centre & 152 & 153 & 17 & 50 & \\
\hline General hospital & 53 & 18 & 7 & 4 & \\
\hline Academic hospital & 58 & 32 & 0 & 0 & \\
\hline Patient and family costs ${ }^{\mathrm{d}}$ & $832(18 \%)$ & $946(21 \%)$ & $1066(30 \%)$ & $585(22 \%)$ & $3182(24 \%)$ \\
\hline $95 \% C I$ & $395-1310$ & $561-1332$ & $601-1531$ & $47-1122$ & $1653-4711$ \\
\hline Cost of formal care & 443 & 274 & 311 & 315 & \\
\hline Cost of informal care & 387 & 639 & 700 & 450 & \\
\hline Devices & 1 & 4( & 4( & 3 & \\
\hline Costs in other sectors ${ }^{\mathrm{b}, \mathrm{d}}$ & $1367(30 \%)$ & $562(12 \%)$ & $448(13 \%)$ & 442 (17\%) & $1896(14 \%)$ \\
\hline $95 \% C I$ & 836-1991 & $271-853$ & $175-722$ & $131-755$ & $1149-2643$ \\
\hline Productivity losses & 1367 & 610 & 297 & 405 & \\
\hline Total cost $\mathrm{t}^{\mathrm{d}}$ & 4594 & 4497 & 3501 & 2609 & 13,216 \\
\hline $95 \%$ CI & $3814-5454$ & $3681-5313$ & $2828-4173$ & $1943-3275$ & $11089-15343$ \\
\hline
\end{tabular}

a Significant differences found in categories between baseline and 12 months after.

b Significant differences found in categories between baseline and 6 months after.

c MEG is only performed within 3 months prior to the 3-month measurement.

d Mean costs are based on multiple imputations using predictive mean matching $(\mathrm{N}=116)$.

e Calculated with the last observation carried backwards to reflect costs during 12 months.

f Assessment at baseline covered the period of three months before inclusion in the study and hence before start of the diagnostic trajectory.

Table 3

Mean costs per participant (in Euros; 2015) and 95\% confidence intervals for main cost categories separately for people diagnosed with epilepsy and people diagnosed as not having epilepsy (or for whom it is still uncertain).

\begin{tabular}{|c|c|c|c|c|c|}
\hline & Baseline & 3 months after & 6 months after & 12 months after & Total annual costs ${ }^{\mathrm{b}}$ \\
\hline \multicolumn{6}{|l|}{ Healthcare costs ${ }^{\mathrm{a}}$} \\
\hline No epilepsy or uncertain $(95 \% \mathrm{CI})$ & 2235 (1778-2692) & $2903(1838-3967)$ & $2476(1415-3536)$ & $1626(1352-1900)$ & $8630(6643-10,618)$ \\
\hline Diagnosed with epilepsy (95\%CI) & 2401 (2002- 2799) & $3026(2461-3590)$ & 1766 (1522-2010) & 1575 (1304-1847) & $7942(692-8964)$ \\
\hline \multicolumn{6}{|l|}{ Patient and family costs ${ }^{a}$} \\
\hline No epilepsy or uncertain $(95 \% \mathrm{CI})$ & $427(110-744)$ & $914(192-1636)$ & $730(285-1175)$ & $355(0-754)$ & $2354.805(980-3730)$ \\
\hline Diagnosed with epilepsy (95\%CI) & $1070(379-1761)$ & $912(398-1425)$ & $1234(544-1924)$ & $702(0-1522)$ & 3550 (1234-5867) \\
\hline \multicolumn{6}{|l|}{ Costs in other sectors ${ }^{a}$} \\
\hline No epilepsy or uncertain $(95 \% \mathrm{CI})$ & $1059(1-2118)$ & $523(0-1052)$ & $981(100-1861)$ & $178(0-408)$ & $1859.024(733-2985)$ \\
\hline Diagnosed with epilepsy $(95 \% \mathrm{CI})$ & $1586(810-2361)$ & $567(212-923)$ & $248(92-405)$ & $352(167-537)$ & 1520 (974-2067) \\
\hline \multicolumn{6}{|l|}{ Total cost ${ }^{\mathrm{a}}$} \\
\hline No epilepsy or uncertain $(95 \% \mathrm{CI})$ & $3722(2494-4949)$ & $4340(2607-6073)$ & $4187(2728-5645)$ & $2159(1574-2744)$ & $12,844(9827-15,862)$ \\
\hline Diagnosed with epilepsy $(95 \% \mathrm{CI})$ & $5057(3913-6200)$ & $4505(3508-5502)$ & $3248(2426-4071)$ & $2630(1735-3525)$ & $13,013(10,128-15,898)$ \\
\hline
\end{tabular}

${ }^{\text {a }}$ Mean costs are based on multiple imputations using predictive mean matching. Number of people diagnosed as having epilepsy $\mathrm{N}=76$; number of people diagnosed as not having epilepsy or uncertain $\mathrm{N}=33$ ).

$\mathrm{b}$ Does not include baseline costs. 
Table 4

Mean utilities and health scores per patients related to HR-QoL measured before and 12 months after an optimized diagnostic procedure.

\begin{tabular}{llllll}
\hline & Baseline $^{\mathrm{b}}$ & $\begin{array}{l}3 \text { months } \\
\text { after }\end{array}$ & $\begin{array}{l}6 \text { months } \\
\text { after }\end{array}$ & $\begin{array}{l}12 \text { months } \\
\text { after }\end{array}$ & Overall $^{\mathrm{a}}$ \\
\hline $\begin{array}{c}\text { Total sample } \\
\text { Utilities }\end{array}$ & 0.80 & 0.81 & 0.80 & 0.84 & $0.81^{\mathrm{a}}$ \\
$\begin{array}{c}\text { No epilepsy or } \\
\text { uncertain } \\
\text { Utilities }\end{array}$ & 0.77 & 0.84 & 0.82 & 0.86 & 0.83 \\
$\begin{array}{c}\text { Diagnosed with } \\
\text { epilepsy }\end{array}$ & 0.81 & 0.79 & 0.79 & 0.84 & 0.81 \\
\hline Utilities & & & & & \\
\hline
\end{tabular}

a Reflects the average annual QALY during the year of the study based on area under the curve method.

b Assessment at baseline covered the period of three months before inclusion in the study and hence before start of the diagnostic trajectory.

specialized epilepsy center, and is likely to treat more severe or complicated cases. This could impede the generalizability of the results, as these cases are already more likely to use healthcare resources. Third, the EQ-5D is a tool for assessing the HR-QoL of a general population. As other literature indicated, the EQ-5D might not be an appropriate instrument to measure HR-QoL in epilepsy patients, since it does not cover chronic difficulties to which the patient has adapted (Selai et al., 1999; Wijnen et al., 2017). A solution to this would be to use a more disease-specific tool such as the Quality of Life in Epilepsy Inventory to increase sensitivity (QOLIE) (Cramer et al., 1999). Fourth, as the study used self-report instruments, recall-bias by the respondents, or proxies, is likely. Nevertheless, a recall period from 1 to 4 months has been established as an acceptable period to maintain the validity of results related to resource consumption (Evans and Crawford, 1999). Fifth, given the static design of this study with measurements at fixed time points and the continuous reevaluation of patients' health status after additional examinations, we were not able to investigated the immediate impact of a diagnosis on a patients' quality of life. However, it is likely that most patients have completed most of their diagnostic trajectory at 6 months after baseline.

Furthermore, as shown in the results section, costs related to diagnosis had not decreased. This can be explained by the inability of patients to specify appliances. Hence, patients may have wrongly indicated that they had been subjected to one or more given procedures, leading to an overestimation of costs. For example, a similar study found that patients reported implausible estimates of diagnostic procedures which they had undergone, such as MEG and EEG (Wijnen et al., 2014). In addition, the use of healthcare devices may be underrepresented because the questionnaire item was a voluntary, openended question. Lastly, travel costs, as well as costs of unemployment, incapacity, and mortality were not taken into account, as they were too difficult to measure. To resolve these issues, future research should include more specific items focusing on traveling costs and use of medical devices.

\subsection{Conclusion}

To conclude, significant reductions in costs and improvements in quality of life were observed which might be attributable to the optimized diagnostic trajectory especially in the early phase. The average 3monthly costs per patient had decreased towards the end of the study, where costs in other sectors (i.e. productivity losses) had decreased the most drastically. Healthcare costs were the largest expenses and had significantly decreased at the end of the study. As chronic care patients make diverse costs, future research should identify the long-term costs after an optimized diagnostic trajectory for patients with epilepsy, possibly identifying patients who are at high risk of becoming high-cost users in the future. Moreover, an assessment of the incremental costeffectiveness of this optimal diagnostic treatment would be needed in order to draw firm conclusions regarding its cost-effectiveness.

Our findings are roughly similar to other studies and can be seen as complementary given that there are no identical studies that are oriented on the influence of diagnosis on the burden of disease of epilepsy, differentiating between people diagnosed with epilepsy during the follow-up of the study and the people who are diagnosed as not having epilepsy or for whom diagnosis is still uncertain. The current study offers promising insights on the effects of diagnostic improvements on decreasing the burden of disease of epilepsy or similar neurological conditions.

\section{Declarations of interest}

None.

\section{Acknowledgements}

The authors thank M. Savelkoul and E. Vos for their contribution to the data collection, the Academic Center of Epileptology, Kempenhaeghe, as well as all patients enrolled in the study that participated and made this research possible. In addition we would like to thank Nico Akemann, Ndedi Sijsma, Karin Plugge, Marlous van den Hoek, Marieke Alting Siberg, and Peter-Jan Ris from the Vrije Universiteit MEG center. This study was partly based on a project funded by the 'Innovatiefonds zorgverzekeraars Nederland' (Dutch innovation fund health insurers).

\section{References}

Angus-Leppan, H., 2008. Diagnosing epilepsy in neurology clinics: a prospective study. Seizure 17 (5), 431-436.

Baker, G.A., et al., 1997. Quality of life of people with epilepsy: a European study. Epilepsia 38 (3), 353-362.

Benbadis, S.R., 2006. The EEG in nonepileptic seizures. J. Clin. Neurophysiol. 23 (4), 340-352.

Caller, T.A., et al., 2016. A cognitive behavioral intervention (HOBSCOTCH) improves quality of life and attention in epilepsy. Epilepsy Behav. 57, 111-117.

Chadwick, D., Smith, D., 2002. The misdiagnosis of epilepsy: the rate of misdiagnosis and wide treatment choices are arguments for specialist care of epilepsy.(Editorials). Br. Med. J. 324 (7336), 495-497.

Cockerell, O.C., et al., 1994. The cost of epilepsy in the United Kingdom: an estimation based on the results of two population-based studies. Epilepsy Res. 18 (3), 249-260.

Cramer, J.A., et al., 1999. Development of the quality of life in epilepsy inventory for adolescents: the QOLIE-AD-48. Epilepsia 40 (8), 1114-1121.

Dodrill, C.B., Morris, G.L., 2001. Effects of vagal nerve stimulation on cognition and quality of life in epilepsy. Epilepsy Behav. 2 (1), 46-53.

Drummond, M., et al., 2005. Methods for the Economic Evaluation of Health Care Programmes. Oxford University Press, New York.

Evans, C., Crawford, B., 1999. Patient self-reports in pharmacoeconomic studies. Pharmacoeconomics 15 (3), 241-256.

Grittner, U., et al., 2011. Missing value imputation in longitudinal measures of alcohol consumption. Int. J. Methods Psychiatr. Res. 20 (1), 50-61.

Hakkaart-van Roijen, L., et al., 2015. Kostenhandleiding: Methodologie Van Kostenonderzoek En Referentieprijzen Voor Economische Evaluaties in De Gezondheidszorg. Institute for Medical Technology Assessment: Erasmus Universiteit Rotterdam.

Horton, N.J., Lipsitz, S.R., 2001. Multiple imputation in practice: comparison of software packages for regression models with missing variables. Am. Stat. 55 (3), 244-254.

Hosseini, N., et al., 2016. Effect of motivational interviewing on quality of life in patients with epilepsy. Epilepsy Behav. 55, 70-74.

Ivanova, M.J.I., et al., 2010. Economic burden of epilepsy among the privately insured in the US. Pharmacoeconomics 28 (8), 675-685.

Kind, P., et al., 2009. The use of QALYs in clinical and patient decision-making: issues and prospects. Value Health 12 (s1), S27-S30.

Lamers, L., et al., 2005. [Measuring the quality of life in economic evaluations: the Dutch EQ-5D tariff]. Ned. Tijdschr. 149 (28), 1574-1578.

Noachtar, S., Rémi, J., 2009. The role of EEG in epilepsy: a critical review. Epilepsy Behav. 15 (1), 22-33.

Pugliatti, M., et al., 2007. Estimating the cost of epilepsy in Europe: a review with economic modeling. Epilepsia 48 (12), 2224-2233.

Ramaratnam, S., Baker, G.A., Goldstein, L.H., 2008. Psychological treatments for epilepsy. Cochrane Database Syst. Rev.(3).

Rice, D., 1994. Cost-of-illness studies: fact or fiction? The Lancet 344 (8936), 1519-1520.

Selai, C., Elstner, K., Trimble, M., 1999. Quality of life pre and post epilepsy surgery. 
Epilepsy Res. 38 (1), 67-74.

Slobbe, L., et al., 2011. Kosten van ziekten in Nederland 2007: trends in de Nederlandse zorguitgaven 1999-2010. RIVM rapport 27, 0751023.

Stavem, K., Bjørnæs, H., Lossius, M.I., 2001. Properties of the 15D and EQ-5D utility measures in a community sample of people with epilepsy. Epilepsy Res. 44 (2), 179-189.

Tetto, A., et al., 2002. The costs of epilepsy in Italy: a prospective cost-of-illness study in referral patients with disease of different severity. Epilepsy Res. 48 (3), 207-216.

Van Reenen, M., Oppe, M., 2015. EQ-5D-3L User Guide: Basic Information on How to Use the EQ-5D-3L Instrument (Version 5.1). EuroQol Group.
Weinstein, M.C., Torrance, G., McGuire, A., 2009. QALYs: the basics. Value Health 12 (s1), S5-S9.

Westerhuis, W., et al., 2011. Coping style and quality of life in patients with epilepsy: a cross-sectional study. J. Neurol. 258 (1), 37-43.

Wijnen, B., et al., 2014. Eliciting patients' preferences for epilepsy diagnostics: a discrete choice experiment. Epilepsy Behav. 31, 102-109.

Wijnen, B.F., et al., 2017. A comparison of the responsiveness of EQ-5D-5L and the QOLIE-31P and mapping of QOLIE-31P to EQ-5D-5L in epilepsy. Eur. J. Health Econ. $1-10$. 